\title{
Release of toxic methylene blue from water by mesoporous silicalite-1: characterization, kinetics and isotherm studies
}

\author{
Sabarish Radoor ${ }^{1} \cdot$ Jasila Karayil $^{2} \cdot$ Aswathy Jayakumar ${ }^{1} \cdot$ Jyotishkumar Parameswaranpillai $^{1} \cdot$ Suchart Siengchin $^{1}$
}

Received: 12 February 2021 / Accepted: 19 May 2021 / Published online: 5 June 2021

(c) The Author(s) 2021

\begin{abstract}
In the present work, we have developed a mesoporous silicalite-1 using CMC as a template for the removal of MB from aqueous solution. The synthesized silicalite-1 were characterized using scanning electron microscopy (SEM), transmission electron microscopy (TEM), Fourier transform infrared spectroscopy (FT-IR), X-ray diffraction (XRD), thermogravimetric analysis (TGA), Energy-dispersive X-ray spectroscopy (EDAX) and $\mathrm{N}_{2}$ adsorption-desorption isotherm (BET). XRD and FT-IR analysis confirmed the formation of crystallinity and development of MFI structure in the mesoporous silicalite-1. The adsorption of MB dye on mesoporous silicalite-1 was conducted by batch adsorption method. The effect of various parameters such as adsorbent dosage, initial dye concentration, contact time and temperature on the dye uptake ability of silicalite-1 was investigated. The operating parameters for the maximum adsorption are silicalite- 1 dosage $(0.1 \mathrm{wt} \%)$, contact time (240 min), initial dye concentration $(10 \mathrm{ppm})$ and temperature $\left(30^{\circ} \mathrm{C}\right)$. The MB dye removal onto mesoporous silicalite-1 followed pseudo-second-order kinetic and Freundlich isotherm. The silicalite- 1 exhibits $86 \%$ removal efficiency even after six adsorption-desorption cycle. Therefore, the developed mesoporous silicalite- 1 is an effective eco-friendly adsorbent for MB dye removal from aqueous environment.
\end{abstract}

Keywords Mesoporous $\cdot$ Silicalite-1 $\cdot$ Methylene blue $\cdot$ Adsorption $\cdot$ Kinetics

\section{Introduction}

In the last few decades, the quality of water is declining in an alarming rate. Dyes are one of the major pollutants which deteriorate our water resources such as river, lake, etc. (Wang and Ariyanto 2007; Wang et al. 2008; Radoor et al. 2020a) Synthetic dyes constitute about $90 \%$ of the total dye used in various industries such as paints, textiles, paper, printing, plastics and cosmetics (Gupta 2009; Sabarish and Unnikrishnan 2018a, b). Azo dye, anthraquinones dyes, phthalocyanines and polymethines are the common

Sabarish Radoor

sabarishchem@gmail.com

Suchart Siengchin

suchart.s.pe@tggs-bangkok.org

1 Materials and Production Engineering, The Sirindhorn International Thai-German Graduate School of Engineering (TGGS), King Mongkut's University of Technology North Bangkok, Bangkok 10800, Thailand

2 Government Women's Polytechnic College, Calicut, Kerala, India examples of synthetic dyes which are frequently employed for different application (Forgacs et al. 2004; Ali 2010). Dye dissemination into water bodies is not only aesthetically unpleasant but also causes some major issues such as low dissolved oxygen (DO) level, high BOD level and obstruction for sunlight transmission through water (Ali 2010; Radoor et al. 2020b; Mahdavi et al. 2012; El-Shamy 2020). Thus, it adversely affects the aquatic organism (ElShamy 2020). Dyes effluent also cause serious health risk to humans such as hypersensitivity, allergy, asthma, kidney dysfunction, liver and brain disorder (Chung 2016; Mani et al. 2019; Rafatullah et al. 2010). Methylene blue (MB) are recalcitrant pollutant with cariogenic and mutagenic nature. It is generally used for dying cotton, silk and wool. The structural formula of MB is shown in Fig. 1. It causes several health issues such as eye burns, skin irritation, vomiting and nausea to humans (Shi et al. 2015; Kumar and Jena 2016; Kumari et al. 2016).

The excessive use of dye raises concern and hence its removal from aqueous effluent has become a challenging topic for researchers and scientists. Researchers have designed several novel materials for dye removal by adopting 
<smiles>CN(C)c1ccc2nc3ccc(N(C)C)cc3[s+]c2c1</smiles>

Fig. 1 Structural formula of methylene blue

technologies such as adsorption, coagulation, oxidation, filtration, ultrafiltration, etc. (Mallick 2002; Bayat et al. 2018; Alver and Metin 2012). Due to simplicity, low-cost and high efficiency, adsorption is considered as one of the most effective method for dye removal (Anbia and Salehi 2012; Brião et al. 2017). Activated carbon and nanoparticle are effective adsorbent for dye removal applications; however due to high cost and low efficiency its large-scale usage is limited (Aysan et al. 2016). Recently, various low-cost and ecofriendly adsorbent were reported for removing dyes from wastewater including zeolites, kaolin, clay, montmorillonite, activated carbon, agricultural waste, etc. (Aysan et al. 2016; Jawad and Abdulhameed 2020; Chaari et al. 2019; Preetha and Vishalakshi 2020; Ahmad et al. 2020; Mahmoodi et al. 2018) Silicalite-1 belongs to family of zeolite and possesses aluminium free MFI type framework. High surface area and porous nature enable it to use in different application such as adsorption, catalyst and fine chemical industrial applications (Yin et al. 2020; Yang et al. 2020).

Jing et al. (2016) fabricated $\mathrm{TiO}_{2}$-loaded silicalite-1 for degradation of rhodamine $\mathrm{B}$. They reported that adsorbent dosage plays a key role in dye removal efficiency as they observed a significant increment in dye removal efficiency with adsorbent dosage. Cheng et al. (2017) reported that $\mathrm{GO} /$ silicalite-1 composite is as an effective adsorbent for rhodamine B. The maximum adsorption capacity $(56.55 \mathrm{mg} / \mathrm{g}$ ) was observed at $\mathrm{pH}=3$ within $30 \mathrm{~min}$ of contact time. Recently, our team fabricated sodium alginatemodified silicalite- 1 for rhodamine B removal. The modified silicalite-1 displayed high removal efficiency than conventional silicalite- 1 probably due to the high surface area and pore diameter. The reusability test was also conducted to check the industrial advantage. The result proved that sodium alginate-modified silicalite-1 exhibits good regeneration capacity (Sabarish and Unnikrishnan 2018c).

There is only limited research available for dye adsorption studies on silicalite- 1 from wastewater. So, in this work, we made an attempt to evaluate the dye (MB) adsorption capacity of carboxymethyl cellulose (CMC)modified silicalite- 1 . The effect of different parameters such as initial dye concentration, contact time, temperature, dosage on the adsorption process was also discussed in details. The adsorption kinetics and isotherm on adsorption process is also presented.

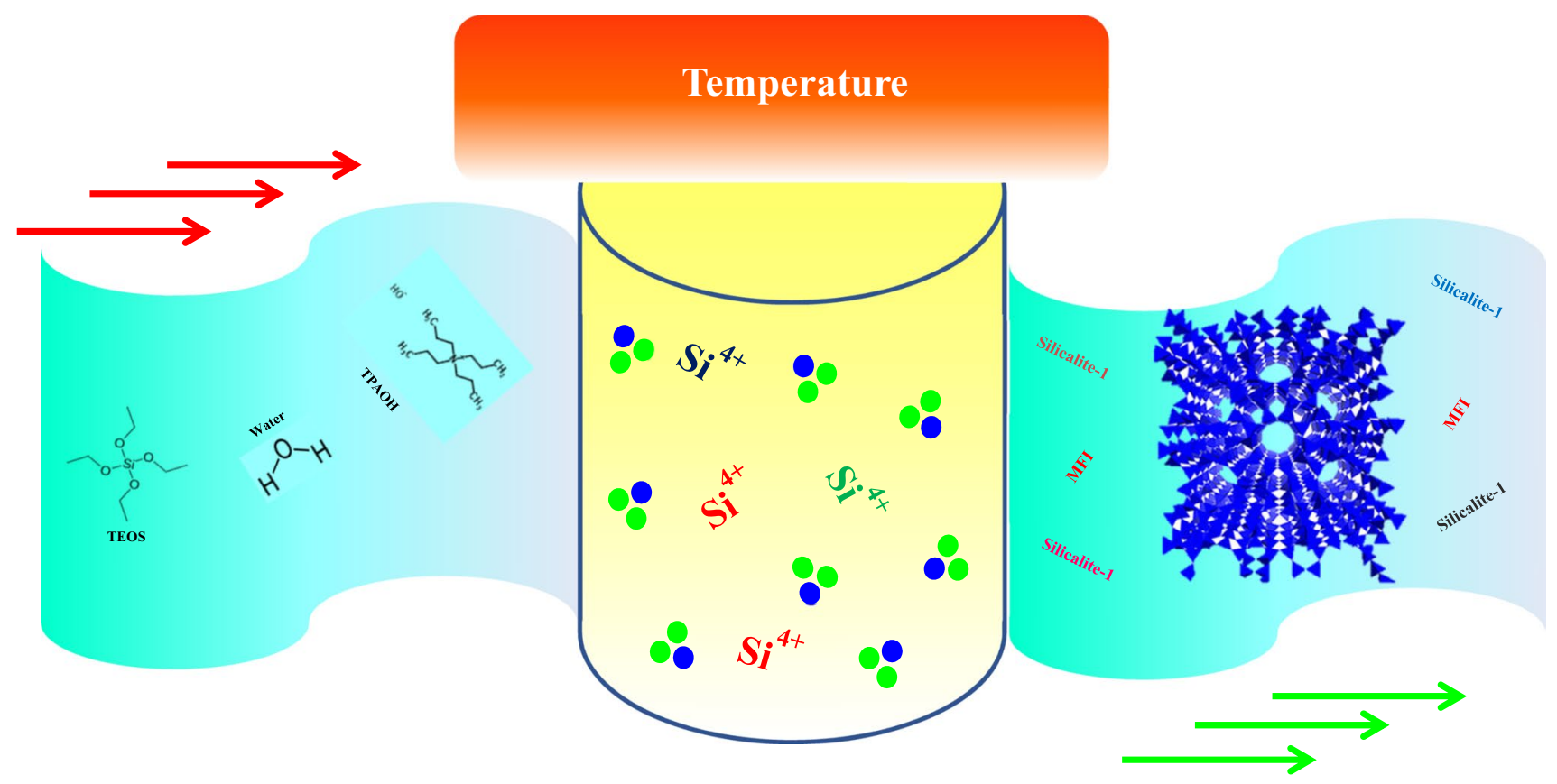

Scheme 1 Schematic diagram of silicalite-1 


\section{Materials and methods}

\section{Chemicals}

Tetrapropylammonium hydroxide $\left(\left(\mathrm{CH}_{3} \mathrm{CH}_{2} \mathrm{CH}_{2}\right)_{4} \mathrm{NOH}\right.$; TPAOH) and tetraethylorthosilicate $\left(\mathrm{C}_{8} \mathrm{H}_{20} \mathrm{O}_{4} \mathrm{Si}\right.$; TEOS $)$ were purchased from Sigma Aldrich Co. Ltd (India). Carboxymethyl cellulose $\left(\left[\mathrm{C}_{6} \mathrm{H}_{7} \mathrm{O}_{2}(\mathrm{OH})_{\mathrm{x}}\left(\mathrm{OCH}_{2} \mathrm{COONa}\right)_{\mathrm{y}}\right]_{\mathrm{n}}\right.$, $\mathrm{CMC})$, and methylene blue $\left(\mathrm{C}_{16} \mathrm{H}_{18} \mathrm{Cl} \mathrm{N} \mathrm{N}_{3} \mathrm{~S}, \mathrm{MB}\right)$ were purchased from Merck Co. Ltd (India). All the chemicals were used as such without further purification.

\section{Synthesis of mesoporous silicalite-1}

The mesoporous silicalite- 1 was synthesized by adopting hydrothermal method. In a typical synthesis, $3.49 \mathrm{~g}$ of tetrapropylammonium hydroxide (TPAOH) and $3.1 \mathrm{~g}$ of tetraethyl orthosilicate (TEOS) were mixed in distilled water under constant stirring for $5 \mathrm{~h}$. After wards, $0.2 \mathrm{~g}$ of CMC is mixed to the above solution with constant stirring. The solution was concentrated in a rotavapor at $80^{\circ} \mathrm{C}$ for $30 \mathrm{~min}$ to form a viscous solution. The resulting sol was introduced into a stainless autoclave for crystallization at $80{ }^{\circ} \mathrm{C}$ for $24 \mathrm{~h}$ followed by high temperature treatment at $175^{\circ} \mathrm{C}$ for $8 \mathrm{~h}$. The obtained product was filtered, washed with water, dried and finally calcined at $550{ }^{\circ} \mathrm{C}$ for $5 \mathrm{~h}$ to remove the organic components. For comparison purpose, conventional silicalite- 1 was prepared with similar procedure without adding template, CMC. The schematic diagram for the synthesis of silicalite-1 is shown in Scheme 1. (Sabarish and Unnikrishnan 2017, 2019).

\section{Characterization}

Powder X-ray diffraction (XRD) patterns in the range of $5-50^{\circ}$ were obtained with a Rigaku Miniflex 600 diffractometer using $\mathrm{CuK} \alpha$ radiation at a scanning speed of $4 \% \mathrm{~min}$. The characteristic vibration bands were identified by Jasco 4700 FT-IR spectrometer with $\mathrm{KBr}$ pellet. Scanning electron microscopic (SEM) images were recorded by using a Hitachi SU6600 Variable Pressure Field Emission Scanning Electron Microscope (SEM). Transmission electron microscopic images (TEM) were taken with a JEOL JEM-2100 transmission electron microscope operated at an accelerating voltage of $200 \mathrm{kV}$. The thermal stability of the uncalcined sample was analysed by thermogravimetric (TGA) analysis with Q50 instrument at a heating rate of $10{ }^{\circ} \mathrm{C} / \mathrm{min}$ in nitrogen atmosphere. $\mathrm{N}_{2}$ adsorption/desorption isotherm were employed to find out the surface area and pore size distributions at $77 \mathrm{~K}$ with Micromeritics Gemini V-2380 surface area analyser. Before measurement the sample was outgassed at $573 \mathrm{~K}$ for $3 \mathrm{~h}$. The $\mathrm{Si} / \mathrm{Al}$ ratio of the samples was determined by electron dispersive spectroscopy (EDAX) using JEOL JED-2300 instrument.

\section{Adsorption experiment}

For adsorption studies, stock solution of MB (100 ppm) was prepared in distilled water. 10, 20, 30, 40 and $50 \mathrm{ppm}$ of dye solution was prepared by diluting the stock solution. The $\mathrm{pH}$ of the dye solution was adjusted using $\mathrm{HCl}$ and $\mathrm{NaOH}$. The effect of the environmental parameters on dye removal was studied by varying adsorbent loading $(0.02-0.10 \mathrm{wt} \%)$, dye concentration (10-50 ppm), contact time (20-330 min) and temperature $\left(30-60{ }^{\circ} \mathrm{C}\right)$. Batch adsorption experiment was employed to find out the adsorption capacity of MB onto the mesoporous silicalite-1 sample. The dye uptake performance was assessed by soaking $0.10 \mathrm{wt} \%$ of silicalite- 1 in $50 \mathrm{~mL}$ of MB dye at different temperature. After predetermined time intervals the sample was withdrawn, filtered and the solution was measured using UV-Vis spectrophotometer at $\lambda_{\max } \sim 668 \mathrm{~nm}$. From the calibration curve, the concentration of dye in the sample is noted. The experiments were done in triplicate and the average value is reported.

The percentage removal and equilibrium concentration were calculated as follows

$q_{\mathrm{e}}=\frac{\left(C_{0}-C_{\mathrm{S}}\right) V}{W}$

$R=\frac{C_{0}-C_{\mathrm{e}}}{C_{0}} \times 100(\%)$

where $C_{0}$ and $C_{\mathrm{e}}$ are the initial and equilibrium dye concentration $\left(\mathrm{mg} \mathrm{L}^{-1}\right), V$ is the volume of dye solution $(\mathrm{L})$; and $W$ is weight $(\mathrm{g})$ of the adsorbent.

\section{Desorption experiment}

Desorption experiment of MB on silicalite-1 was performed by immersing $0.10 \mathrm{wt} \%$ of mesoporous silicalite- 1 sample in $50 \mathrm{~mL}$ of MB solution (10 ppm, temperature- $30{ }^{\circ} \mathrm{C}$ ). After complete equilibrium time, the silicalite- 1 was separated and eluted with $0.1 \mathrm{~mol} / \mathrm{L} \mathrm{HCl}$ to desorb the dye. The silicalite- 1 was later washed with distilled water, dried and used for next cycle (Huang et al. 2019).

\section{Result and discussion}

Figure 2 shows the XRD patterns of conventional and mesoporous silicalite-1. Both silicalite-1 exhibits typical MFI framework structure with five characteristic peaks at $7.98^{\circ}, 8.82^{\circ}, 23.18^{\circ}, 24.02^{\circ}$ and $24.46^{\circ}$ corresponds to

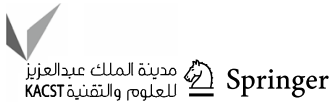



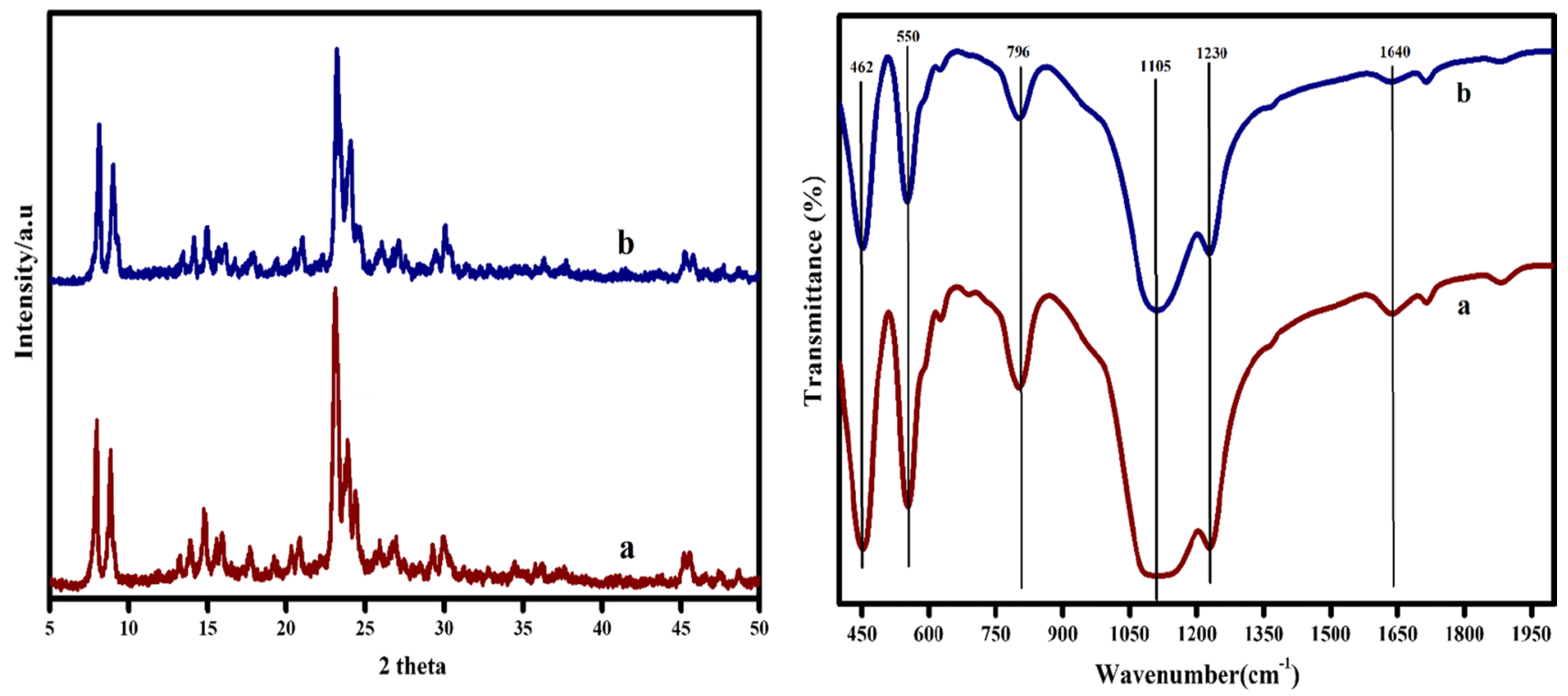

Fig. 2 Powder XRD patterns and FT-IR spectra of conventional and mesoporous silicalite-1

(101), (020), (503), (151) and (303) reflection, respectively. However, with the addition of template the peak intensity of silicalite- 1 slightly reduces, probably due to the development of mesopores. Thus, CMC template is efficient to generate mesoporosity in silicalite-1 without compromising its crystallinity (Sabarish and Unnikrishnan 2019; Ling et al. 2018). To understand the chemical composition of silicalite-1, we performed FT-IR spectroscopy. The FT-IR spectra of conventional and mesoporous silicalite- 1 are displayed in Fig. 2. The strong absorption band at $550 \mathrm{~cm}^{-1}$ is attributed to double five membraned ring which is characteristic of MFI framework. The band at $796 \mathrm{~cm}^{-1}$ and $1105 \mathrm{~cm}^{-1}$ are assigned to $\mathrm{Si}-\mathrm{O}-\mathrm{Si}$ external symmetric stretching $\left(\mathrm{SiO}_{4}\right.$ tetrahedra) and $\mathrm{Si}-\mathrm{O}-\mathrm{Si}$ internal asymmetric stretching $\left(\mathrm{SiO}_{4}\right.$ tetrahedra). The band at $1230 \mathrm{~cm}^{-1}$ is attributed to external asymmetric stretching of $\mathrm{Si}-\mathrm{O}$ bond. A weak band observed at $1640 \mathrm{~cm}^{-1}$ could be due to the adsorbed water present in the sample. Finally, the absorption band at $462 \mathrm{~cm}^{-1}$ is due to $\mathrm{Si}-\mathrm{O}-\mathrm{Si}$ rocking. FT-IR studies were thus complimentary to XRD study and confirmed the successful synthesis of silicalite-1 (Sabarish and Unnikrishnan 2018c; Yang et al. 2016).

The morphology of conventional and mesoporous silicalite-1 was evaluated by SEM and TEM analysis (Figs. 3 and 4). The SEM image of mesoporous silicalite-1 (Fig. 3) shows a rough surface with sphere like particle in the range of $10-30 \mathrm{~nm}$. The result thus suggests the formation of mesopore in the system, which is attributed to the removal of templates. TEM images further confirmed that mesoporous silicalite- 1 have pore diameter in the range of
$10-30 \mathrm{~nm}$. The prominent lattice fringes seen in the TEM images imply a high crystallinity for the sample and are complementary to the previous reported work (Wang et al. 2020) (Fig. 4). The elemental composition of mesoporous silicalite-1 is detected using EDAX measurement (Fig. 5). The analysis indicates that the synthesized sample contains only $\mathrm{Si}$ and $\mathrm{O}$, thus confirming the product is silicalite- 1 . $\mathrm{N}_{2}$ adsorption/desorption isotherm were employed to characterize the surface area and porosity of the sample. Figure 6I illustrates the $\mathrm{N}_{2}$ adsorption/desorption isotherm of conventional and mesoporous silicalite-1. As shown in Fig. $6 \mathrm{a}$, the conventional silicalite- 1 belongs to type 1 isotherm with major uptake of gas at a relative low pressure $(P / \mathrm{Po}<0.2)$. This indicates the presence of only micropores in the system. However, mesoporous silicalite- 1 exhibits a prominent hysteresis loop at $P / \mathrm{Po}=0.25$ to 0.9 due to the capillary condensation of nitrogen. The result thus indicates the co-existence of micro- and mesopores in the modified sample. BJH (Barrett-Joyner-Halenda) pore size distribution is shown in Fig. 6(II). It is evident from figure that conventional silicalite- 1 has only micropores $(<2 \mathrm{~nm})$, whereas the mesoporous silicalite-1 have pore diameter in the range of $10-30 \mathrm{~nm}$, thus confirming the presence of mesopores. This study further confirms that mesoporosity is generated in CMC templated sample.

The thermal stability of conventional and mesoporous silicalite- 1 is compared by thermogravimetric analysis (Fig. 7). The conventional silicalite- 1 showed $16 \%$ of total weight loss at $100-250{ }^{\circ} \mathrm{C}$ and $300-500{ }^{\circ} \mathrm{C}$. This is attributed to the loss of water and TPAOH, respectively, from the 

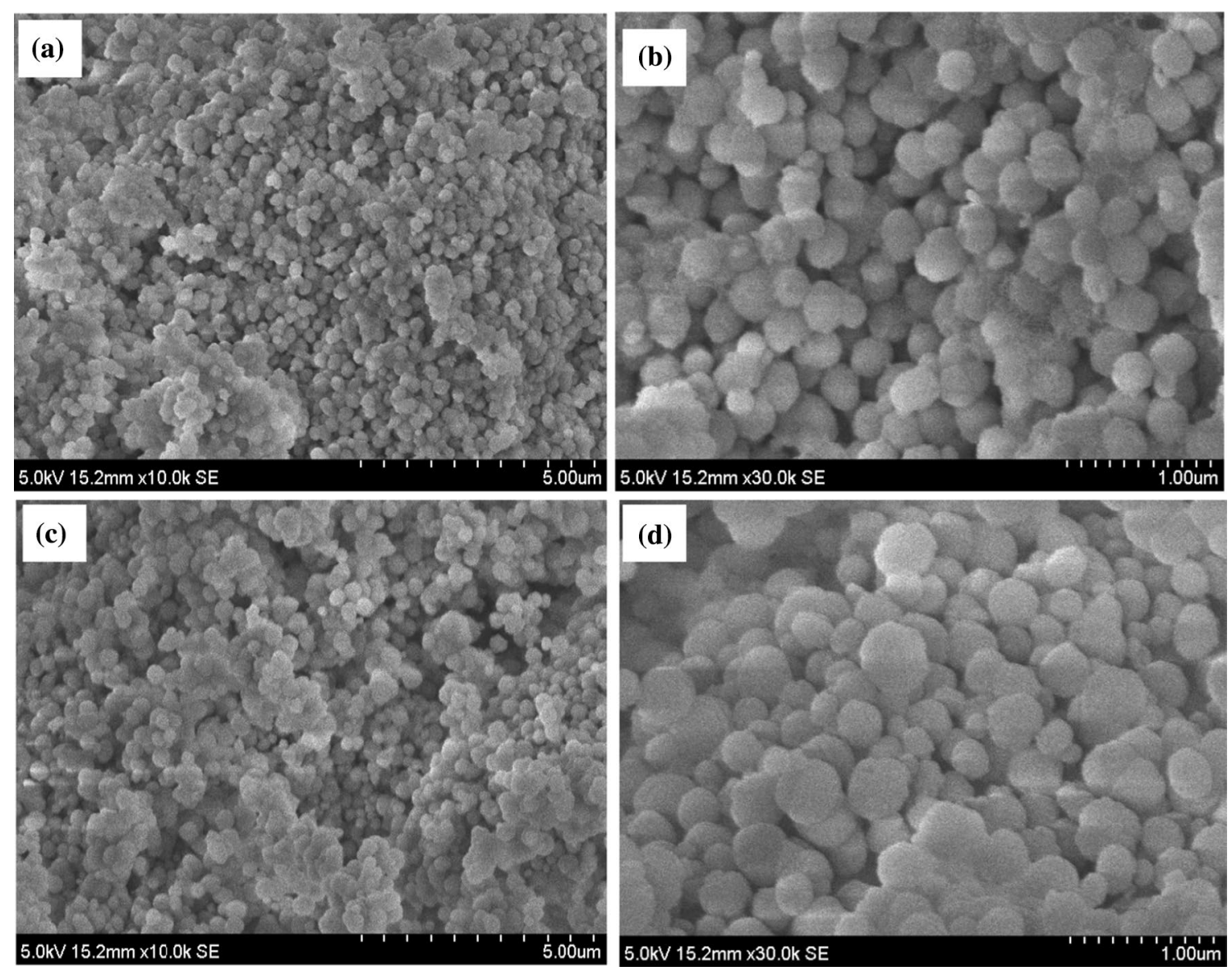

Fig. 3 SEM micrographs of $\mathbf{a}, \mathbf{b}$ conventional and $\mathbf{c}, \mathbf{d}$ mesoporous silicalite-1

Fig. 4 TEM images of mesoporous silicalite-1

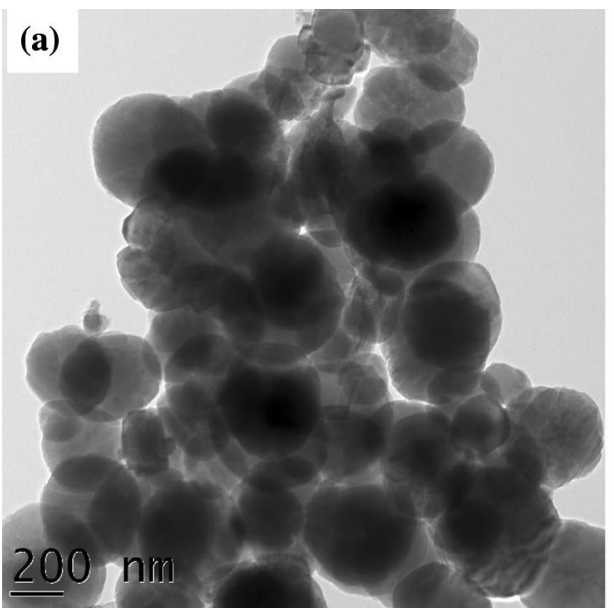

(b)

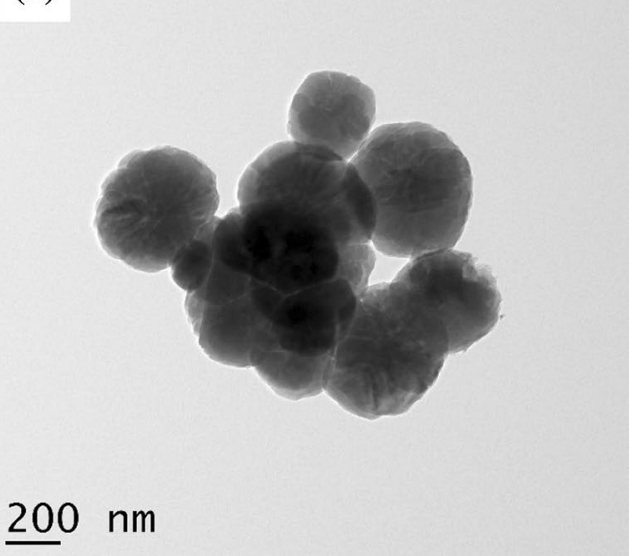

silicalite-1 framework. In the case of mesopores silicalite-1, a third weight loss appears at $500{ }^{\circ} \mathrm{C}$ which is due to the decomposition of template. As modified silicalite- 1 possess higher weight loss (22\%) than conventional silicalite-1, it is thermally more stable than conventional silicalite- 1 .

\section{Adsorption experiment of mesoporous silicalite-1 on methylene blue}

Due to the presence of micro- and mesoporous structure, modified silicalite- 1 is expected to have good adsorption capacity for dye molecule. This prompted us to monitor the 
Fig. 5 EDAX image of mesoporous silicalite-1
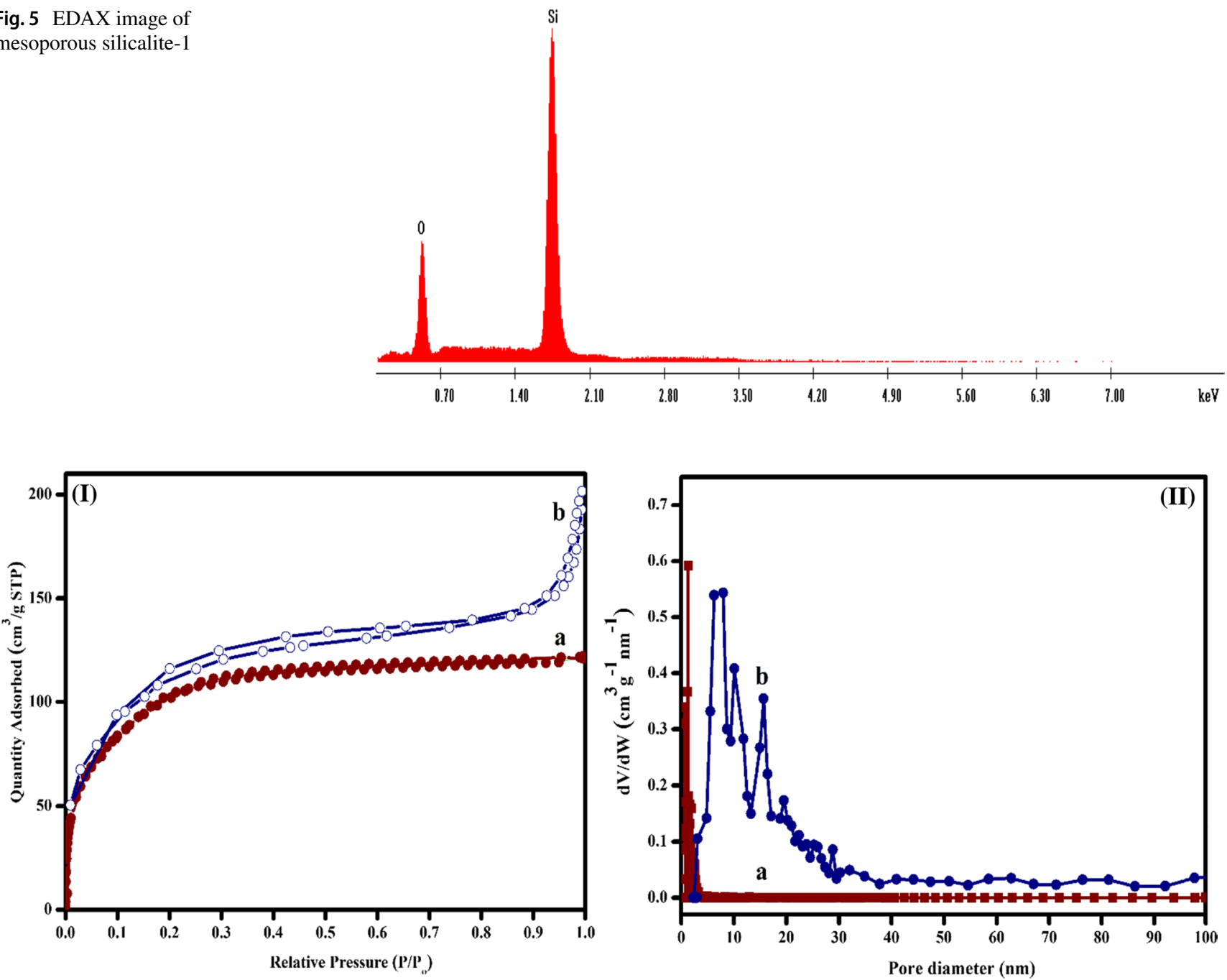

Fig. 6 I $\mathrm{N}_{2}$ adsorption isotherms of: a conventional $\mathbf{b}$ mesoporous silicalite-1; II pore size distribution of: a conventional b mesoporous silicalite-1

dye (MB) uptake ability of modified silicate. The influence of environmental parameters such as silicalite-1 dosage, temperature, initial dye concentration and contact time was also investigated in detail. The influence of silicate dosage on the MB removal was carried out by varying the silicalite- 1 from 0.02 to $0.10 \mathrm{wt} \%$. From Fig. 8a, it can clearly see that the dye adsorption capacity increases linearly with adsorbent dosage. High surface area along with the presence of micro/ mesoporous structure on silicalite- 1 could have increases the affinity of dye molecule to the adsorbent. Consequently, adsorption capacity increases and a maximum adsorption capacity $(4 \mathrm{mg} / \mathrm{g})$ was achieved at $0.10 \mathrm{wt} \%$ of adsorption dosage. The relationship between initial dye concentration and adsorption capacity of MB is shown in Fig. 8b. It is evident from figure that when the initial dye concentration increases from 10 to $50 \mathrm{ppm}$, the adsorption capacity increases from 4 to $16.45 \mathrm{mg} / \mathrm{g}$. Similar results have also been reported by Duman et al. (2020). They observed that on increasing the initial dye concentration from 20 to $40 \mathrm{mg} / \mathrm{L}$ the adsorption capacity increases from 8 to $15 \mathrm{mg} / \mathrm{g}$. Dong et al. (2011) reported that mesoporous SBA-15 exhibits high adsorption capacity when the initial concentration exceeds $230 \mathrm{mg} / \mathrm{g}$. According to the authors high initial concentration provides a necessary driving force for the diffusion of dye from aqueous to the solid phase. We have varied the immersing time from 10 to $330 \mathrm{~min}$ and evaluate its effect on the MB adsorption was in the following operational conditions initial dye concentration $-10 \mathrm{ppm}$, temperature- $30{ }^{\circ} \mathrm{C}$ and dosage- $0.1 \mathrm{wt} \%$. In the initial contact time, due to availability of large number of unoccupied active sites on the surface of adsorbent, the rate of adsorption increases, Therefore, adsorption capacity steeply rises in the initial phase of contact time. However, the rate of adsorption becomes gradual $120 \mathrm{~min}$ and eventually at $240 \mathrm{~min}$ it reaches 


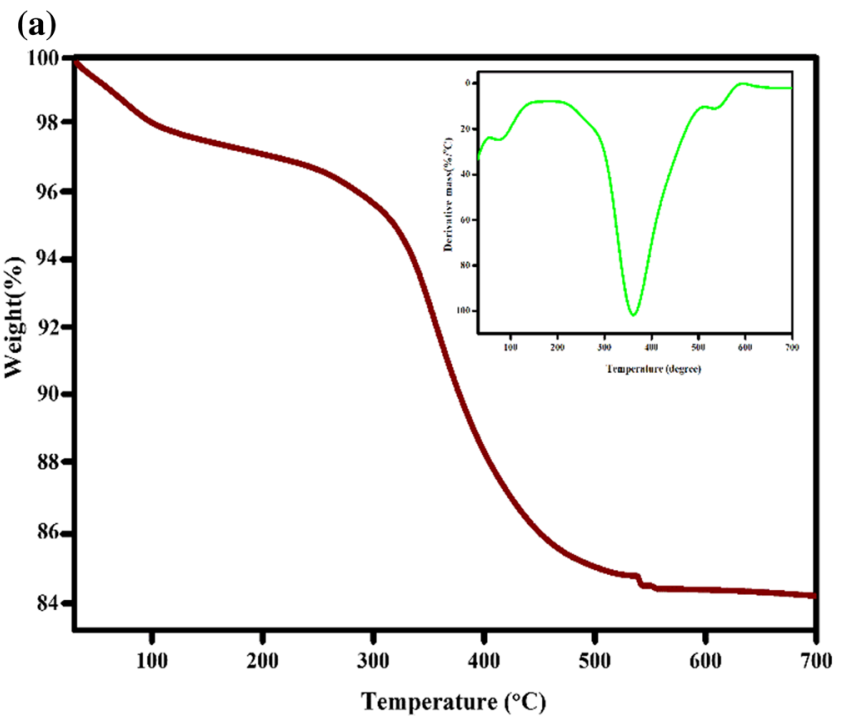

(b)

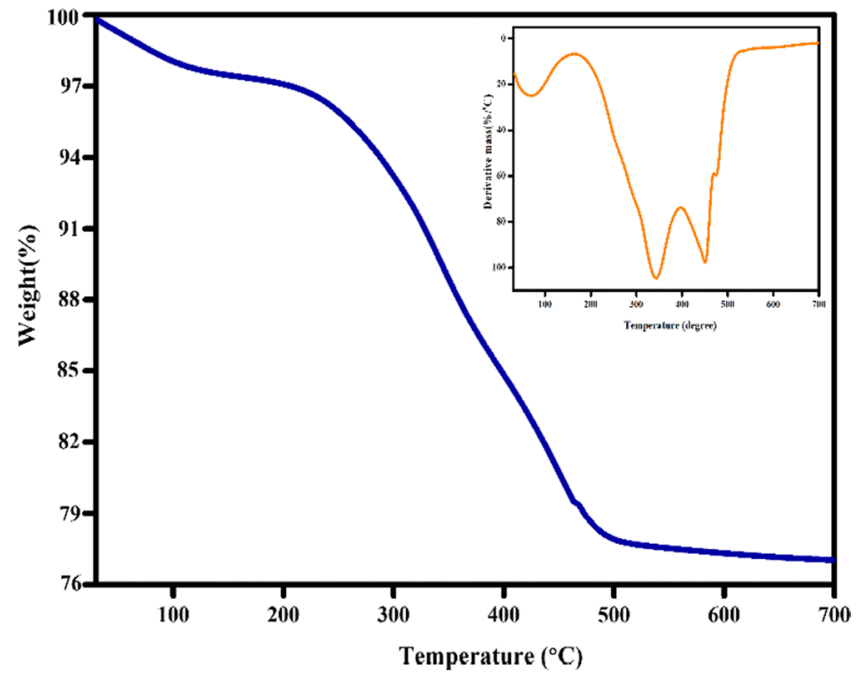

Fig. 7 TGA curves of conventional and mesoporous silicalite-1 and the corresponding DTG curves are given at the inset
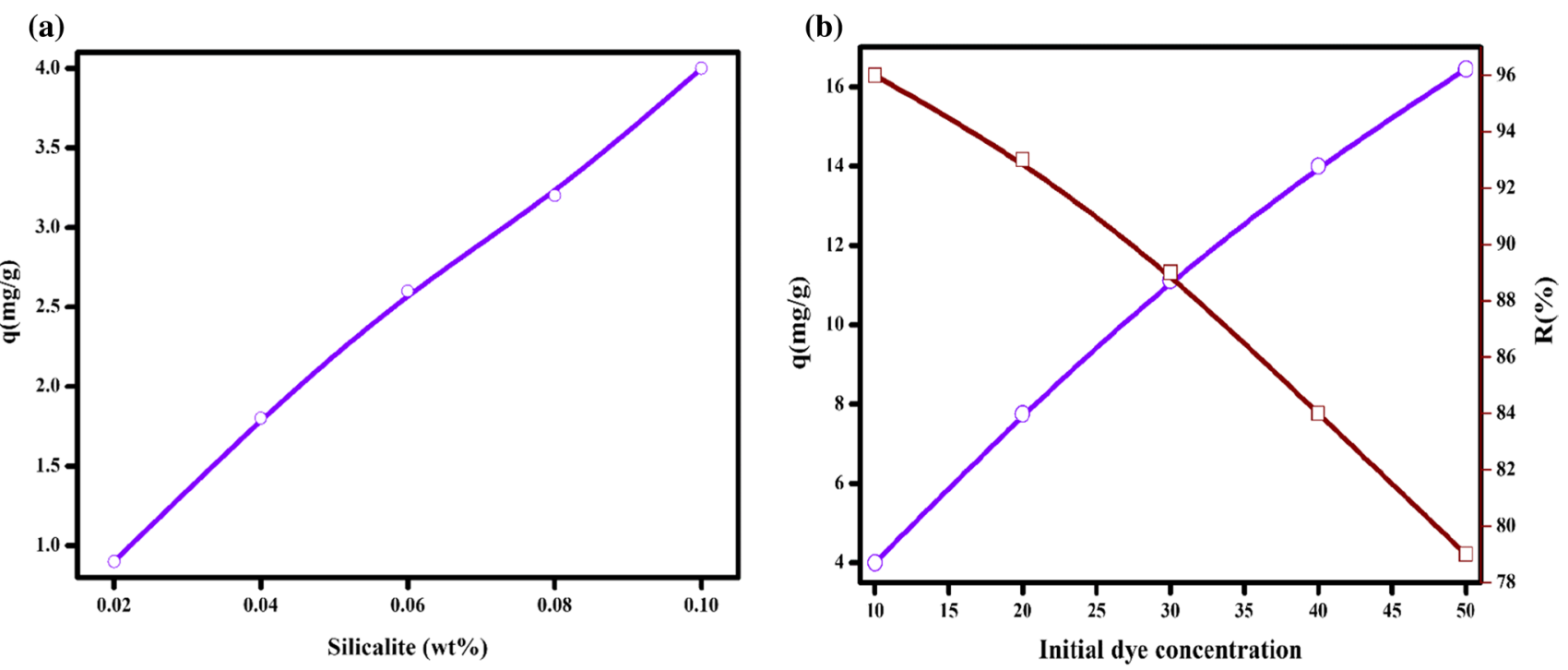

(c)

(d)
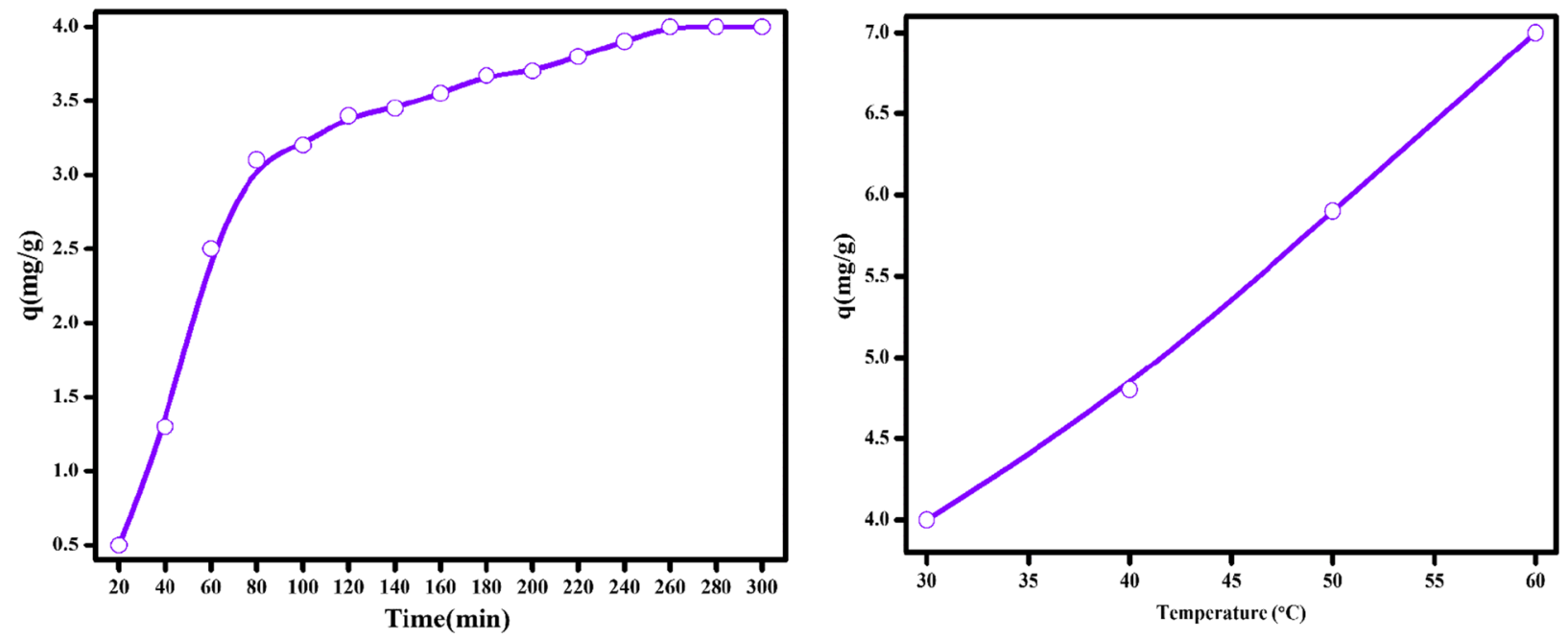

Fig. 8 Effect of various parameters on the adsorption of $\mathrm{MB}$ onto mesoporous silicalite-1 a silicalite- 1 dosage $\mathbf{b}$ initial dye concentration $\mathbf{c}$ contact time $\mathbf{d}$ temperature on the adsorption process (adsor-

bent dosage $=0.10 \mathrm{wt} \%$, initial $\mathrm{MO}$ concentration $=10 \mathrm{ppm}$, contact time $=240 \mathrm{~min}$ and temperature $=30^{\circ} \mathrm{C}$ 
constant. This implies that the adsorption site on the surface of silicalite- 1 gets saturated with contact time and after 240 min complete occupation of adsorption site happens. Similar curve was noted by Mouni et al. they obtained equilibrium at $120 \mathrm{~min}$ (Mouni et al. 2018). Figure $8 \mathrm{~d}$ shows the adsorption capacity at different temperature $\left(30-60^{\circ} \mathrm{C}\right)$. On increasing the temperature from 30 to $60^{\circ} \mathrm{C}$, the adsorption capacity increases from 4 to $7 \mathrm{mg} / \mathrm{g}$, thus suggesting that the MB adsorption on silicalite-1 is endothermic. High temperature tends to enhance the mobility of dye molecule. As a result, the dye molecule can easily diffuse from the solution phase to the adsorbent phase. Therefore, high temperature favours the MB adsorption on silicalite-1. Scheme 2 shows the schematic representation of interaction of mesoporous silicalite-1 with MB dye molecule.

\section{Adsorption kinetics}

Adsorption kinetics was investigated to understand the adsorption mechanism and rate of adsorption of MB dye onto adsorbent. The experimental data were evaluated using two well-known models: pseudo-first-order and pseudosecond-order model. The linearized form of pseudo-firstorder kinetic equation is expressed as follows Limousin et al. (2007)

$\log \left(q_{\mathrm{e}}-q_{t}\right)=\log q_{\mathrm{e}}-\frac{K_{1} t}{2.303}$

where $q_{\mathrm{t}}(\mathrm{mg} / \mathrm{g})$ and $q_{\mathrm{e}}(\mathrm{mg} / \mathrm{g})$ are the amount of dye adsorbed at time ' $t$ ' and equilibrium. $K_{1}$ are pseudo-firstorder rate constant in $1 / \mathrm{min}$. The graph of $\log \left(q_{\mathrm{e}}-q_{\mathrm{t}}\right)$ versus $\mathrm{t}$ gives a straight with $k_{1}$ as slope and $q_{\mathrm{e}}$ as intercept.

The pseudo-second-order model is as follow Ho (2006)

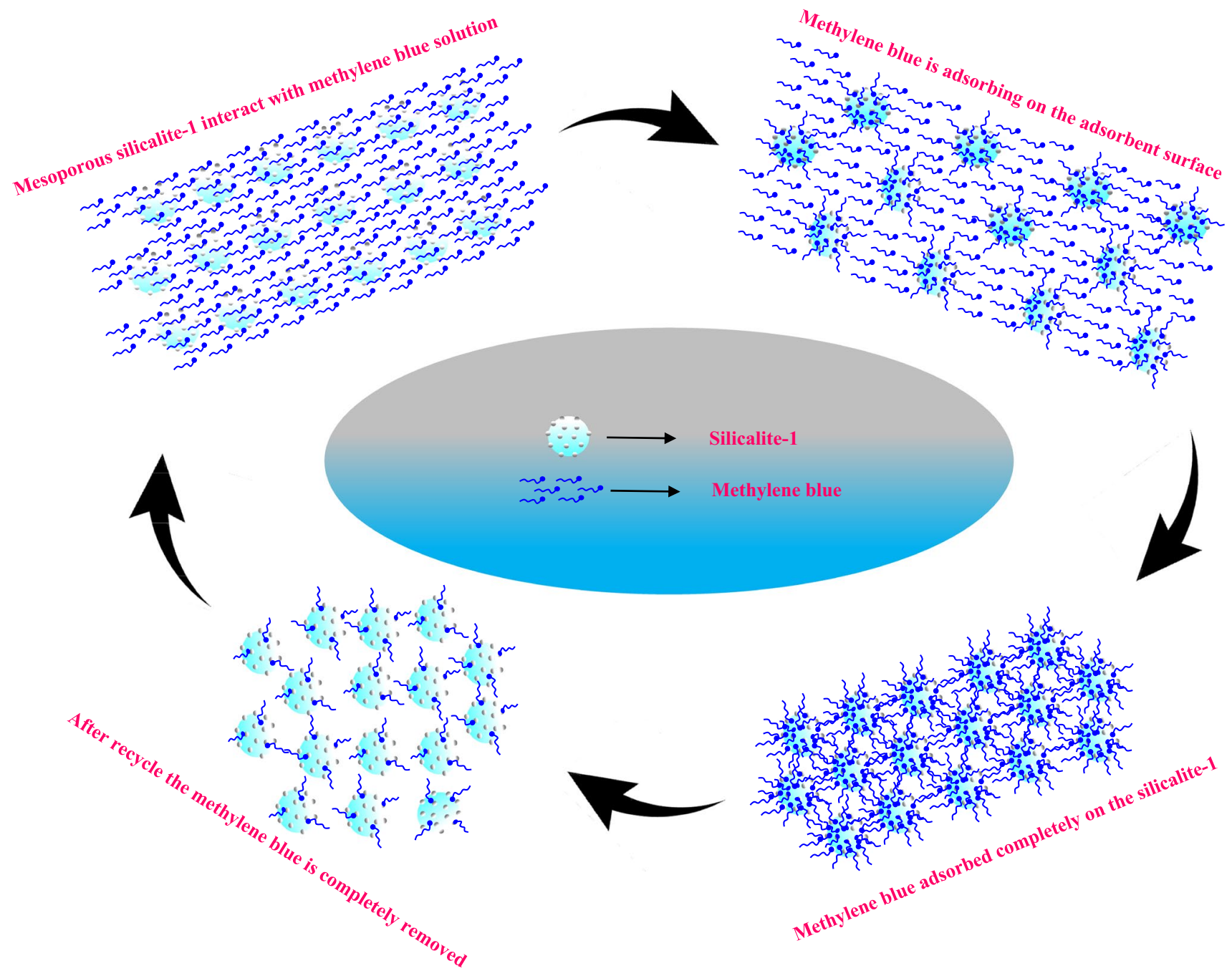

Scheme 2 Mechanism for MB adsorption on mesoporous silicalite-1 
(a)

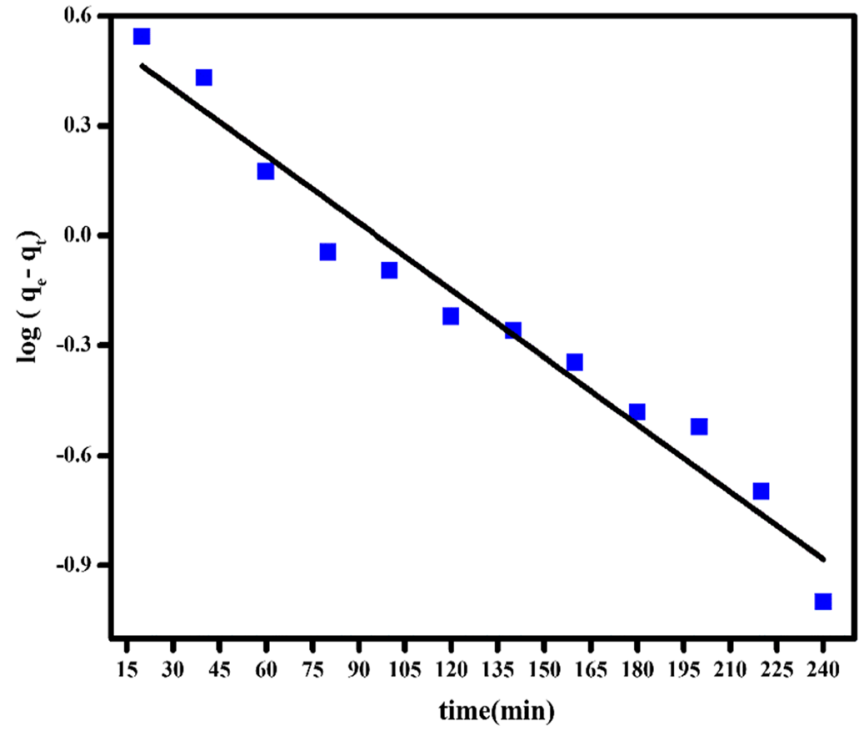

(b)

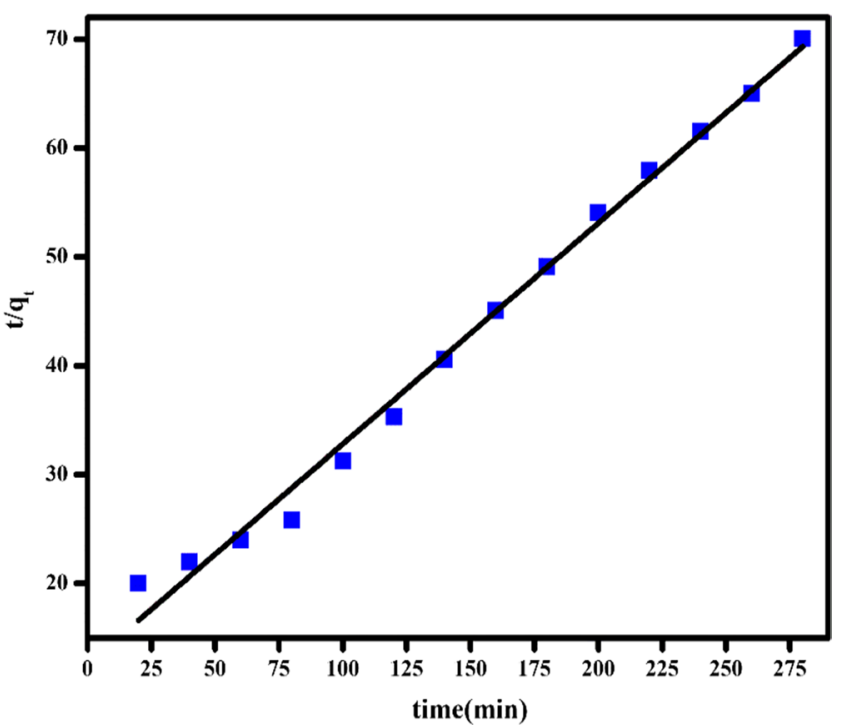

Fig. 9 a pseudo-first-order b pseudo-second-order models for the adsorption of MB dye onto mesoporous silicalite-1

$\frac{t}{q_{\mathrm{e}}}=\frac{1}{K_{2} q_{\mathrm{e}}^{2}}+\frac{t}{q_{\mathrm{e}}}$

where $K_{2}$ is pseudo-second-order rate constant ( $\mathrm{g} / \mathrm{mg} \mathrm{min}$ ) and $q_{\mathrm{e}}$ is equilibrium adsorption capacity. The value of $q_{\mathrm{e}}$ and $K_{2}$ were obtained from the slope and intercept of plot $t$ / $\mathrm{q}_{t}$ versus $t$.

The experimental data fitting on the kinetic model are illustrated in Fig. 9 and the corresponding kinetic data are presented in Table 1 . The validity of these models was checked by noting the correlation coefficient value $\left(R^{2}\right)$. As can be seen, the experimental value fitted well in pseudosecond-order (0.99) model than pseudo-first-order (0.95). In addition to this, the correlation coefficient of pseudosecond-order model is higher than pseudo-first-order model (Fig. 9). Therefore, pseudo-second-order is more suitable than pseudo-first order to explain kinetics of MB uptake on silicalite-1. (a)

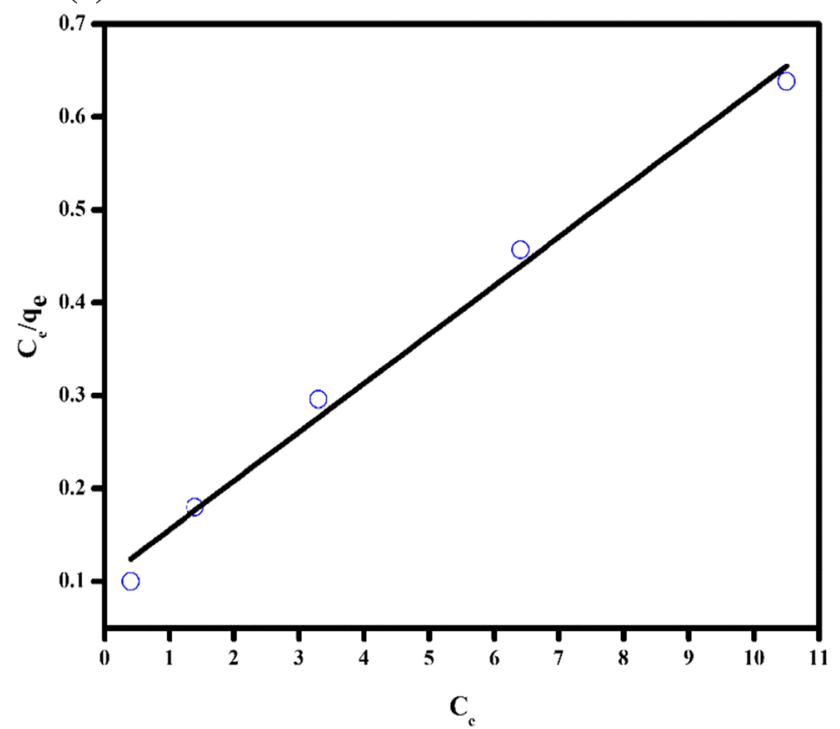

(b)

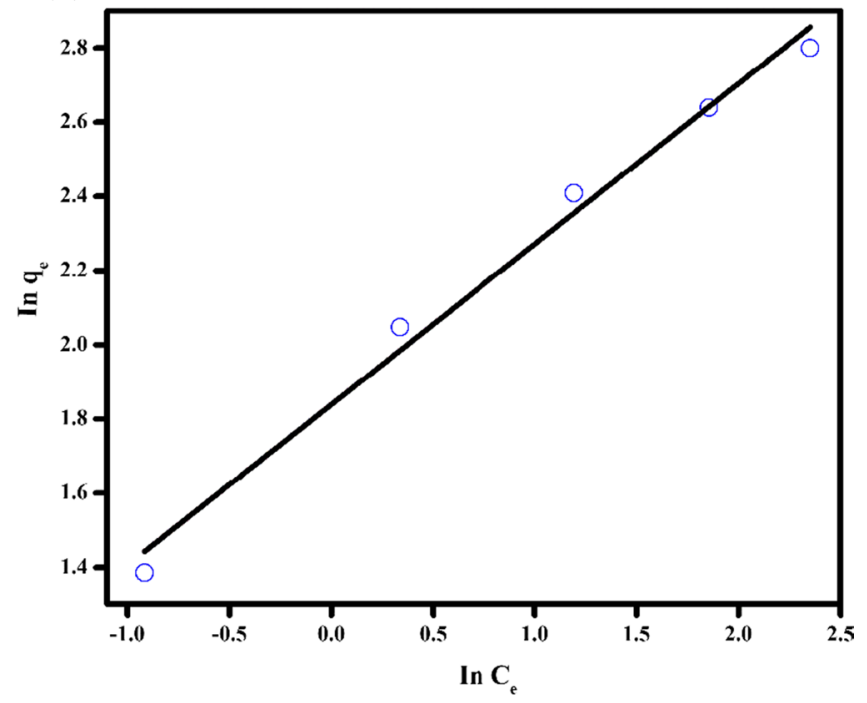

Fig. 10 Isotherm model plots for the adsorption of MB a Langmuir isotherm b Freundlich isotherm 
Table 1 Kinetic parameter values of adsorption kinetics for MB onto mesoporous silicalite-1

\begin{tabular}{|c|c|c|c|c|c|c|}
\hline \multirow{2}{*}{$\begin{array}{l}\text { Experimental } \\
q_{\mathrm{e}}, \exp \left(\mathrm{mg} \mathrm{g}^{-1}\right)\end{array}$} & \multicolumn{3}{|l|}{ PFO } & \multicolumn{3}{|l|}{ PSO } \\
\hline & $K_{1}\left(\min ^{-1}\right)$ & $q_{\mathrm{e}}\left(\mathrm{mg} \mathrm{g}^{-1}\right)$ & $R^{2}$ & $K_{2}\left(\mathrm{~g} \mathrm{mg}^{-1} \min ^{-1}\right)$ & $q_{\mathrm{e}}\left(\mathrm{mg} \mathrm{g}^{-1}\right)$ & $R^{2}$ \\
\hline 4 & -0.0140 & 3.2 & 0.95 & 0.0031 & 3.95 & 0.99 \\
\hline
\end{tabular}

Table 2 Langmuir isotherm and Freundlich isotherm parameter values for $\mathrm{MB}$ adsorption onto mesoporous silicalite-1

\begin{tabular}{|c|c|c|c|c|c|c|}
\hline \multicolumn{2}{|l|}{ Experimental } & \multicolumn{3}{|c|}{ Langmuir isotherm } & \multicolumn{2}{|c|}{ Freundlich isotherm } \\
\hline$q_{\mathrm{e}}, \exp \left(\mathrm{mg} \mathrm{g}^{-1}\right)$ & $R^{2}$ & $q_{\max }\left(\mathrm{mg} \mathrm{g}^{-1}\right)$ & $K_{\mathrm{L}}$ & $R^{2}$ & $K_{\mathrm{F}}\left(\mathrm{mg} \mathrm{g}^{-1}\right)$ & $n$ \\
\hline 4 & 0.977 & 19.04 & 0.509 & 0.995 & 4.3 & 2.31 \\
\hline
\end{tabular}

\section{Adsorption isotherm}

Adsorption isotherm is essential to understand the adsorption behaviour and interaction between the adsorbate and adsorbent. The linear form of Langmuir model is expressed as follows Mohan et al. (2002), Afkhami and Moosavi (2010)

$\frac{C_{\mathrm{e}}}{q_{\mathrm{e}}}=\frac{C_{\mathrm{e}}}{q_{\max }}+\frac{1}{K_{\mathrm{L}} q_{\text {max }}}$

where $q_{\mathrm{e}}$ is the amount of $\mathrm{MB}$ dye adsorbed at equilibrium, $C_{\mathrm{e}}$ is the equilibrium concentration of $\mathrm{MB}$ dye $(\mathrm{mg} / \mathrm{L}), q_{\max }$ is maximum adsorption capacity, $K_{\mathrm{L}}$ and $R_{\mathrm{L}}$ are characteristic Langmuir parameters which is termed as Langmuir adsorption constant and separation factor, respectively. $R_{\mathrm{L}}$ is expressed as

$R_{\mathrm{L}}=\frac{1}{1+K_{\mathrm{L}} C_{\mathrm{o}}}$

Here, $\mathrm{C}_{\mathrm{o}}$ is initial $\mathrm{MB}$ concentration $(\mathrm{mg} / \mathrm{L})$. The value of $R_{L}$ is significant and is related to the feasibility of adsorption. The adsorption process is favourable, if $\mathrm{R}_{\mathrm{L}}$ is between 0 and 1 , unfavourable if $R_{\mathrm{L}}>1 . R_{\mathrm{L}}=0$ and $R_{\mathrm{L}}=1$ indicates reversible and linear adsorption, respectively.

The Langmuir isotherm model assumes a homogeneous surface with equivalent site (Fig. 10a). According to this model, there is no interaction between the adsorbed molecules and hence multilayer adsorption will not occur. From the linear plot of $C_{\mathrm{e}} / q_{\mathrm{e}}$ versus $\mathrm{C}_{\mathrm{e}}$, the value of $q_{\mathrm{e}}$ and $K_{\mathrm{L}}$ is obtained. The Freundlich isotherm on the other hand assume heterogeneous surface and there is no restriction of multilayer formation (Fig. 10b). Therefore, in this model both monolayer and multilayer adsorption can take place. The linearized form of Freundlich model is represented as (Eltaweil et al. 2020)

In $q_{\mathrm{e}}=\frac{1}{n} \operatorname{In} C_{\mathrm{e}}+\operatorname{In}$ where $K_{\mathrm{F}}$ and n are Freundlich constants related to adsorption capacity and degree of adsorption, respectively. The value of $K_{\mathrm{F}}$ and n can be determined from the plot of $\ln q_{\mathrm{e}}$ versus $\ln C_{\mathrm{e}}$.

The data of adsorption process were applied to Langmuir and Freundlich isotherm model and the adsorption parameters are shown in Table 2. Since Freundlich isotherm gives a better fit with high correlation coefficient $\left(R^{2}\right)$ it could be more suitable for MB adsorption. The value of $1 / \mathrm{n}$ is between 0 and 1 indicating that the MB adsorption on mesoporous silicalite- 1 is a favourable process.

\section{Recyclability}

The regeneration performance of the modified silicalite-1 was studied by six adsorption-desorption cycles at fixed adsorbent dose of $0.10 \mathrm{wt} \%$ and initial dye concentration $10 \mathrm{ppm}$. The result is presented in Fig. 11. The result shows that the removal percentage of silicalite- 1 at the first

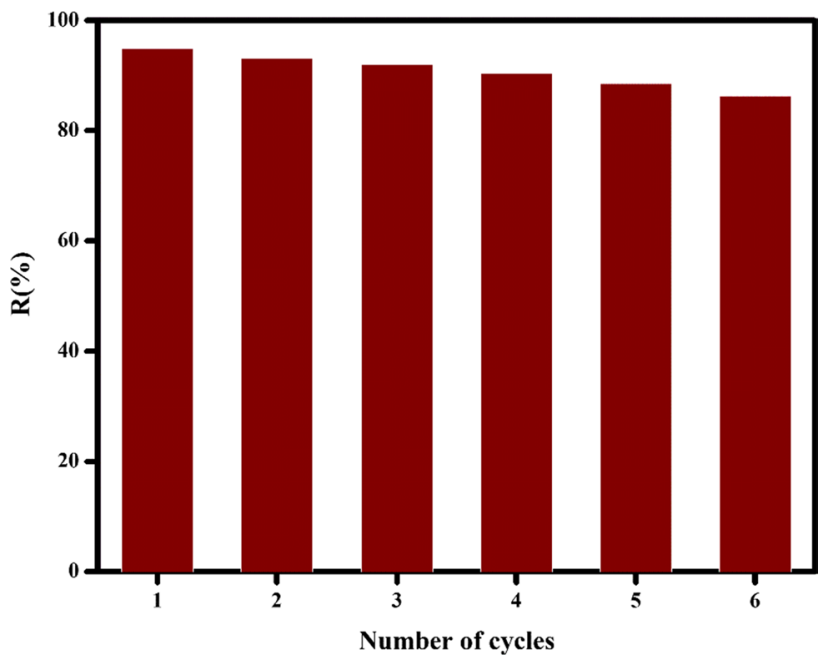

Fig. 11 Reusability performance of adsorption of $\mathrm{MB}$ onto mesoporous silicalite-1 
adsorption-desorption cycle is $95 \%$ and after six adsorption-desorption cycles, the adsorption efficiency was reduced to $86.3 \%$. The results thus demonstrate that the silicalite-1 is effective even after multiple reuses.

In the present study, a mesoporous silicalite-1 was developed using eco-friendly template, CMC. The successful synthesis of modified silicalite- 1 was confirmed by techniques such as SEM, TEM, $\mathrm{N}_{2}$ isotherm, XRD, FT-IR. The synthesized mesoporous silicalite- 1 was effective to remove the cationic dye methylene blue from water. The effect of various operational parameter on the dye adsorption was studied and the result indicates that adsorption is favoured at high initial concentration, high immersing time and high temperature. The dye removal was found to be governed by Freundlich isotherm model and the rate of adsorption was found to obey pseudo-second-order kinetics. The mesoporous silicalite-1 sample also shows excellent recyclability. Therefore, we can conclude that modified silicalite- 1 is a highly attractive candidate for the removal of MB from water.

Acknowledgements The study was financially supported by the King Mongkut's University of Technology North Bangkok (KMUTNB), Thailand through the Post-Doctoral Program (Grant No. KMUTNB63-Post-03 and KMUTNB-64-Post-03 to SR) and (Grant No. KMUTNB-BasicR-64-16)

Author's contribution SR was involved in conceptualization, methodology and writing - original draft. SR, JK and JP were involved in investigation and performed software. SR, AJ and JP were involved in validation. SR, JK, AJ and JP were involved in writing-review and editing. SR, JK and AJ were involved in formal analysis. JK was involved in analysis and interpreted the results. AJ collected the data. SS was involved in editing, funding and supervision.

Funding (Grant No. KMUTNB-63-Post-03 to SR) and (Grant No. KMUTNB-64-03, KMUTNB-BasicR-64-16).

Availability of data and material All data generated or analysed during this study are included in this published article.

\section{Declarations}

Conflict of interest The authors have declared no conflict of interest.

Consent for publication The authors confirm the consent for publication.

Open Access This article is licensed under a Creative Commons Attribution 4.0 International License, which permits use, sharing, adaptation, distribution and reproduction in any medium or format, as long as you give appropriate credit to the original author(s) and the source, provide a link to the Creative Commons licence, and indicate if changes were made. The images or other third party material in this article are included in the article's Creative Commons licence, unless indicated otherwise in a credit line to the material. If material is not included in the article's Creative Commons licence and your intended use is not permitted by statutory regulation or exceeds the permitted use, you will need to obtain permission directly from the copyright holder. To view a copy of this licence, visit http://creativecommons.org/licenses/by/4.0/.

\section{References}

Afkhami A, Moosavi R (2010) Adsorptive removal of Congo red, a carcinogenic textile dye, from aqueous solutions by maghemite nanoparticles. J Hazard Mater 174:398-403

Ahmad MA, Eusoff MA, Oladoye PO, Adegoke KA, Bello OS (2020) Statistical optimization of remazol brilliant blue $\mathrm{R}$ dye adsorption onto activated carbon prepared from pomegranate fruit peel. Chem Data Collect 28:100426

Ali H (2010) Biodegradation of synthetic dyes-a review. Water Air Soil Pollut 213:251-273

Alver E, Metin AÜ (2012) Anionic dye removal from aqueous solutions using modified zeolite: adsorption kinetics and isotherm studies. Chem Eng J 200-202:59-67

Anbia M, Salehi S (2012) Removal of acid dyes from aqueous media by adsorption onto amino-functionalized nanoporous silica SBA-3. Dyes Pigm 94:1-9

Aysan H, Edebali S, Ozdemir C, Celik Karakaya M, Karakaya N (2016) Use of chabazite, a naturally abundant zeolite, for the investigation of the adsorption kinetics and mechanism of methylene blue dye. Microporous and Mesoporous Mater 235:78-86

Bayat M, Javanbakht V, Esmaili J (2018) Synthesis of zeolite/nickel ferrite/sodium alginate bionanocomposite via a co-precipitation technique for efficient removal of water-soluble methylene blue dye. Int J Biol Macromol 116:607-619

Brião GV, Jahn SL, Foletto EL, Dotto GL (2017) Adsorption of crystal violet dye onto a mesoporous ZSM-5 zeolite synthetized using chitin as template. J Colloid Interface Sci 508:313-322

Chaari I, Fakhfakh E, Medhioub M, Jamoussi F (2019) Comparative study on adsorption of cationic and anionic dyes by smectite rich natural clays. J Mol Struct 1179:672-677

Cheng Z-L, Li Y-X, Liu Z (2017) Fabrication of graphene oxide/silicalite-1 composites with hierarchical porous structure and investigation on their adsorption performance for rhodamine B. J Ind Eng Chem 55:234-243

Chung K-T (2016) Azo dyes and human health: a review. J Environ Sci Health C 34:233-261

Dong Y, Lu B, Zang S, Zhao J, Wang X, Cai Q (2011) Removal of methylene blue from coloured effluents by adsorption onto SBA15. J Chem Technol Biotechnol 86:616-619

Duman O, Polat TG, Diker CÖ, Tunç S (2020) Agar/א-carrageenan composite hydrogel adsorbent for the removal of methylene blue from water. Int J Biol Macromol 160:823-835

El-Shamy AG (2020) An efficient removal of methylene blue dye by adsorption onto carbon dot @ zinc peroxide embedded poly vinyl alcohol (PVA/CZnO2) nano-composite: a novel Reusable adsorbent. Polym 202:122565

Eltaweil AS, Ali Mohamed H, Abd El-Monaem EM, El-Subruiti GM (2020) Mesoporous magnetic biochar composite for enhanced adsorption of malachite green dye: characterization, adsorption kinetics, thermodynamics and isotherms. Adv Powder Technol 31:1253-1263

Forgacs E, Cserháti T, Oros G (2004) Removal of synthetic dyes from wastewaters: a review. Environ Int 30:953-971

Gupta VK (2009) Suhas, Application of low-cost adsorbents for dye removal: a review. J Environ Manage 90:2313-2342

Ho Y (2006) Review of second-order models for adsorption systems. J Hazard Mater 136:681-689

Huang T, Yan M, He K, Huang Z, Zeng G, Chen A, Peng M, Li H, Yuan L, Chen G (2019) Efficient removal of methylene blue from aqueous solutions using magnetic graphene oxide modified zeolite. J Colloid Interface Sci 543:43-51

Jawad AH, Abdulhameed AS (2020) Mesoporous Iraqi red kaolin clay as an efficient adsorbent for methylene blue dye: adsorption kinetic, isotherm and mechanism study. Surf Interfaces 18:100422

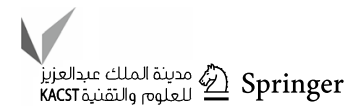


Jing YQ, Wang YC, Gao YZ, Li HQ, Cheng YY, Lu P, Zhang YH, Ma C (2016) Synthesis of TiO2-loaded silicate-1 monoliths and their application for degradation rhodamine B. RSC Adv 6:42495-42501

Kumar A, Jena HM (2016) Removal of methylene blue and phenol onto prepared activated carbon from Fox nutshell by chemical activation in batch and fixed-bed column. J Clean Prod 137:1246-1259

Kumari S, Chauhan GS, Ahn JH (2016) Novel cellulose nanowhiskersbased polyurethane foam for rapid and persistent removal of methylene blue from its aqueous solutions. Chem Eng J 304:728-736

Limousin G, Gaudet JP, Charlet L, Szenknect S, Barthès V, Krimissa M (2007) Sorption isotherms: a review on physical bases, modeling and measurement. Appl Geochem 22:249-275

Ling R, Chen W, Hou J (2018) Preparation of modified MFI (ZSM-5 and silicalite-1) zeolites for potassium extraction from seawater. Particuology 36:190-192

Mahdavi S, Jalali M, Afkhami A (2012) Removal of heavy metals from aqueous solutions using $\mathrm{Fe} 3 \mathrm{O} 4, \mathrm{ZnO}$, and $\mathrm{CuO}$ nanoparticles. In: nanotechnology for sustainable development, pp 171-188

Mahmoodi NM, Taghizadeh M, Taghizadeh A (2018) Mesoporous activated carbons of low-cost agricultural bio-wastes with high adsorption capacity: preparation and artificial neural network modeling of dye removal from single and multicomponent (binary and ternary) systems. J Mol Liq 269:217-228

Mallick N (2002) Biometals 15:377-390

Mani S, Chowdhary P, Bharagava RN (2019) Textile wastewater dyes: toxicity profile and treatment approaches. In: emerging and ecofriendly approaches for waste management, pp 219-244

Mohan D, Singh KP, Singh G, Kumar K (2002) Removal of dyes from wastewater using flyash, a low-cost adsorbent $\dagger$. Ind Eng Chem Res 41:3688-3695

Mouni L, Belkhiri L, Bollinger J-C, Bouzaza A, Assadi A, Tirri A, Dahmoune F, Madani K, Remini H (2018) Removal of methylene blue from aqueous solutions by adsorption on kaolin: kinetic and equilibrium studies. Appl Clay Sci 153:38-45

Preetha BK, Vishalakshi B (2020) Microwave assisted synthesis of karaya gum based montmorillonite nanocomposite: characterisation, swelling and dye adsorption studies. Int J Biol Macromol 154:739-750

Radoor S, Karayil J, Parameswaranpillai J, Siengchin S (2020b) Adsorption study of anionic dye, eriochrome black T from aqueous medium using polyvinyl alcohol/starch/ZSM-5 zeolite membrane. J Polym Environ 28:2631-2643

Radoor S, Karayil J, Parameswaranpillai J, Siengchin S (2020a) Removal of anionic dye Congo red from aqueous environment using polyvinyl alcohol/sodium alginate/ZSM-5 zeolite membrane. Sci Rep 10:1-15
Rafatullah M, Sulaiman O, Hashim R, Ahmad A (2010) Adsorption of methylene blue on low-cost adsorbents: a review. J Hazard Mater 177:70-80

Sabarish R, Unnikrishnan G (2017) Synthesis, characterization and catalytic activity of hierarchical ZSM-5 templated by carboxymethyl cellulose. Powder Technol 320:412-419

Sabarish R, Unnikrishnan G (2018b) PVA/PDADMAC/ZSM-5 zeolite hybrid matrix membranes for dye adsorption: Fabrication, characterization, adsorption, kinetics and antimicrobial properties. J Environ Chem Eng 6:3860-3873

Sabarish R, Unnikrishnan G (2018c) Novel biopolymer templated hierarchical silicalite- 1 as an adsorbent for the removal of rhodamine B. J Mol Liq 272:919-929

Sabarish R, Unnikrishnan G (2018a) Polyvinyl alcohol/carboxymethyl cellulose/ZSM-5 zeolite biocomposite membranes for dye adsorption applications. Carbohyd Polym 199:129-140

Sabarish R, Unnikrishnan G (2019) Synthesis, characterization and evaluations of micro/mesoporous ZSM-5 zeolite using starch as bio template. SN Appl Sci 1:1-13

Shi L, Hu L, Zheng J, Zhang M, Xu J (2015) Adsorptive REMOVAL of methylene blue from aqueous solution using a Ni-Metal organic framework material. J Dispersion Sci Technol 37:1226-1231

Wang S, Ariyanto E (2007) Competitive adsorption of malachite green and $\mathrm{Pb}$ ions on natural zeolite. J Colloid Interface Sci 314:25-31

Wang XS, Zhou Y, Jiang Y, Sun C (2008) The removal of basic dyes from aqueous solutions using agricultural by-products. J Hazard Mater 157:374-385

Wang B, Guo T, Zhang Y, Chen F, Rui P, Xie X, Liao W, Luo Y, Shu X (2020) Cobalt oxide encapsulated hydrophilic hierarchical Silicalite-1 for highly efficient conversion of cyclohexyl hydroperoxide. Microporous Mesoporous Mater 302:110186

Yang H, Yang P, Liu X, Wang Y (2016) Space-confined synthesis of zeolite beta microspheres via steam-assisted crystallization. Chem Eng J 299:112-119

Yang J, Huang Y-X, Pan Y, Mi J-X (2020) Green synthesis and characterization of zeolite silicalite-1 from recycled mother liquor. Microporous Mesoporous Mater 303:110247

Yin C, He J, Liu S (2020) Synthesis of mesoporous silicalite-1 zeolite for the vapor phase Beckmann rearrangement of cyclohexanone oxime. Microporous Mesoporous Mater 307:110517

Publisher's note Springer Nature remains neutral with regard to jurisdictional claims in published maps and institutional affiliations. 